\title{
LÍRICA E ESPAÇO AUTOBIOGRÁFICO EM “SAMBA-CANÇÃO” DE ANA CRISTINA CESAR
}

\author{
Aulus Mandagará Martins*
}

\begin{abstract}
Resumo: O objetivo deste artigo é refletir acerca da dimensão autobiográfica do eu lírico. Para tanto, a partir das noções de pacto autobiográfico, espaço autobiográfico e experiência poética, analisaremos a pertinência das referências biográficas do poema "Samba-canção" de Ana Cristina Cesar.
\end{abstract}

Palavras-chave: Lírica. Autobiografia. Espaço Autobiográfico. Experiência poética. Ana Cristina Cesar.

INTRODUÇÃO

A poesia de Ana Cristina Cesar é marcada pela "tensão entre a confissão e a literatura [...] através de um uso bastante peculiar dos gêneros confessionais, especialmente a correspondência e o diário íntimo", segundo Maria Lucia de Barros Camargo (2003, p. 112). Muito embora esses gêneros confessionais sejam simulacros, quer dizer, obras poéticas que assumem a forma e o tom do diário e da correspondência, nada impede que a poesia de Ana Cristina, na opinião da mesma estudiosa, "se contamine de referências autobiográficas" (CAMARGO, 2003, p. 226), configurando aquilo que Camargo denomina de "confissões da intimidade". A percepção de que a poesia de Ana Cristina é marcada pela confissão é retomada, dentre outros, por Marcos Siscar, que, ao mencionar o "tratamento hiperbólico da experiência pessoal" (SISCAR, 2011, p. 24), alerta para o fato de que essa experiência pessoal é uma "encenação", ou seja, o poema é "desentranhado da vida", mas o evento biográfico é "descontextualizado e recontextualizado, em sua condição de linguagem reconhecível pela convenção de poema" (SISCAR, 2011, p. 13. Grifo do Autor). Nesse sentido, vale lembrar que a poesia de Ana Cristina Cesar se vincula a uma geração de poetas que, em linhas gerais, apostava da sinceridade e na espontaneidade como traços distintivos de uma poética que refutava o aspecto construído e intelectual do poema. Se o vínculo à "poesia marginal" propiciou a Ana Cristina o exercício da intimidade, o tom confessional, intimista e autobiográfico, que caracterizam sua obra, é importante destacar que sua poesia ultrapassa "o discurso biografílico em voga na sua geração" (SISCAR, 2011, p. 14). O objetivo deste artigo é refletir sobre o sentido da "recontextualização" das "referências autobiográficas". Tomemos como ponto de partida o poema "Samba-canção", publicado em A teus pés (1982):

Tantos poemas que perdi

\footnotetext{
Doutor em Letras. Professor de Literatura da Universidade Federal de Pelotas. E-mail: aulus.mm@gmail.com
} 
Tantos que ouvi, de graça,

pelo telefone — taí,

eu fiz tudo pra você gostar,

fui mulher vulgar,

meia-bruxa, meia-fera,

risinho modernista

arranhando na garganta,

malandra, bicha,

bem viada, vândala,

talvez maquiavélica,

e um dia emburrei-me,

vali-me de mesuras

(era uma estratégia),

fiz comércio, avara,

embora um pouco burra,

porque inteligente me punha

logo rubra, ou ao contrário, cara

pálida que desconhece

o próprio cor-de-rosa,

e tantas fiz, talvez

querendo a glória, a outra

cena à luz de spots,

talvez apenas teu carinho,

mas tantas, tantas fiz...

(CESAR, 2013, p. 113)

A evidente exposição do eu, o tom confessional, as marcas linguísticas que identificam um sujeito do sexo feminino, colaboram no sentido de uma possível apreensão da "tensão entre a confissão e a literatura", contaminando o poema de "referências autobiográficas", de modo que o leitor aceite, por inteiro ou pelo menos em parte, que a voz que nele se expressa é a voz de Ana Cristina Cesar. Cabe, então, perguntar, se, de fato, o eu lírico é um eu autobiográfico.

\section{O EU LíRICO É UM EU AUTOBIOGRÁFICO?}

Ao definir o gênero autobiográfico em O pacto autobiográfico (1975), Philippe Lejeune exclui a poesia, fixando-o nos limites da prosa: "narrativa retrospectiva em prosa que uma pessoa real faz de sua própria existência, quando focaliza sua história individual, em particular a história de sua personalidade" (LEJEUNE, 2014, p. 16). A polêmica exclusão da poesia da autobiografia obrigou o autor a refinar sua definição, levando-o a reconhecer a natureza autobiográfica do texto poético. De fato, a exclusão do poema tem algo de contraditório na descrição proposta, uma vez que o próprio Lejeune assinalava que o que verdadeiramente definia a autobiografia não era tanto a forma da linguagem (narrativa em prosa), mas a situação do autor e a posição do narrador, elementos que configuram o "pacto autobiográfico", a célebre identidade autor-narrador-personagem 
principal, pedra basilar de sua definição: "Para que haja autobiografia (e, numa perspectiva mais geral, literatura íntima), é preciso que haja relação de identidade entre o autor, o narrador e o personagem" (LEJEUNE, 2014, p. 18). Em um ensaio posterior, "O pacto autobiográfico (bis)", de 1986, em que faz um balanço da obra de 1975, sobretudo a partir dos debates que ela originou no contexto acadêmico, Lejeune procura encerrar a discussão em torno da exclusão da poesia, reconhecendo seu pleno direito de ser, ela também, autobiográfica, reprisando a tese anteriormente exposta, ou seja, a poesia é autobiográfica pelas mesmas razões que qualquer narrativa: "emprego de um 'eu' claramente autobiográfico, garantido pelo nome do próprio autor, em lugar do 'eu' lírico tradicional" (LEJEUNE, 2014, p. 75).

Como se observa, a teoria de Lejeune toca em uma questão crucial, a saber, a natureza do eu lírico. O eu lírico é um eu autobiográfico, ou, por outras palavras, o eu lírico é uma "pessoa real"? A resposta de Lejeune é, ao que tudo indica, afirmativa, desde que se estabeleça o pacto autobiográfico e se cumpra a condição da identificação do eu lírico com o autor do poema. Neste sentido, sua posição parece consolidar a percepção talvez ainda dominante, principalmente no imaginário do senso comum, mas não apenas, de que o gênero lírico é essencialmente subjetivo, em virtude do papel central que o "eu" aí desempenha. Assim, na poesia lírica o "eu" que se expressa pode ser entendido como a manifestação do próprio poeta, na acepção de sujeito empírico responsável pela criação do poema. Nesta perspectiva, toda poesia lírica seria fundamentalmente autobiográfica, em decorrência da identidade entre o eu lírico e o autor. No entanto, essa dimensão autobiográfica é posta em crise pela crítica moderna que entende o eu lírico (e toda primeira pessoa que se enuncia em textos literários) como uma ficção, quer dizer, uma entidade que só existe no plano do enunciado e, portanto, sem um nexo necessário e causal entre o que se expressa no poema e sua referencialidade, no caso, a vida do poeta.

O problema da natureza do eu lírico possui uma longa tradição no pensamento crítico, conforme demonstra Dominique Combe (2010) ao historicizar o debate, sobretudo na crítica alemã, que se aplica "essencialmente à descrição e à análise do funcionamento do texto poético e à presença textual do sujeito, confluindo para a exigência de uma crítica interna" (2010, p. 112). O debate (que não se restringe, naturalmente, ao cenário da poesia de língua alemã) estabelece-se a partir das intuições dos poetas românticos, que postulavam, em linhas gerais, o poema como a plena expressão do eu criador, de modo a confundir sujeito lírico e sujeito empírico. Deste amplo debate, gostaríamos, contudo, de sublinhar que a percepção romântica é contestada, como já se disse, pela crítica moderna, que prefere atribuir ao eu lírico uma dimensão mais linguística do que referencial, alegando, conforme Roman Ingarden (apenas para citar uma das posições do pensamento alemão, mencionadas por Combe), que, numa obra literária (e, por extensão, no poema), toda enunciação é "fingida", o que não permitiria a distinção do "verdadeiro" e do "falso", anulando, desse modo, a possibilidade de vincular o eu lírico a uma experiência vivida, anterior e exterior ao ato linguístico que consubstancia o poema.

Muito embora o ensaio “A morte do autor” não considere o gênero poético, parecenos que lança alguns pontos interessantes para a reflexão da natureza autobiográfica ou não do eu lírico. A argumentação de Roland Barthes vai no sentido de subverter o vínculo, 
algo perverso, autor-obra, em que o primeiro elo tem supremacia sobre o segundo, de modo a configurar uma tirania do autor: "a cultura corrente está tiranicamente centralizada no autor" (BARTHES, 2004, p. 58). Barthes postula, inicialmente, que não se pode identificar a voz que se manifesta em um texto nem com o herói da narrativa, nem com o indivíduo empírico responsável pelo texto, nem com o autor que expressa ideias literárias, sabedoria universal ou quaisquer outros princípios. Isto porque "a escritura é a destruição de toda voz, de toda origem", lugar em que se perde toda identidade, "a começar pela do corpo que escreve" (2004, p. 57). Ao anunciar a morte do autor, e fazendo ruir seu império, Barthes tem como alvo um determinado tipo de crítica que enfatiza justamente a pessoa do autor, "sua história, seus gostos, suas paixões" (2004, p. 58). Trata-se, como se sabe, daquela crítica que lê a obra a partir da biografia do seu autor, que busca uma explicação da obra em quem a produziu, transformando-a em um enigma a ser decifrado pela chave da sua vida, este "autor-presença" que reivindica um nexo necessário e causal com a obra, seu princípio produtor e explicativo, fonte suprema de significado e valor da obra (HANSEN, 1992, pp. 18-19).

É por passar ao largo dessas questões incontornáveis quanto à noção de autor ou, mais especificamente, eu lírico, que julgamos que a análise da dimensão autobiográfica da poesia prevista por Lejeune é problemática, pelo menos nos termos propostos, uma vez que não aprofunda a questão da natureza do eu lírico, contentando-se com a identificação, promovida pelo pacto autobiográfico, entre o eu que se expressa no poema e seu autor - identidade que depende de uma espécie de supremacia do nome próprio do autor sobre o "eu lírico tradicional". Contudo, o próprio Lejeune fornece uma sugestão que nos parece mais interessante para pensar a dimensão autobiográfica do eu lírico. Trata-se de noção de espaço autobiográfico.

\section{O PACTO FANTASMÁTICO}

A partir de um lugar-comum, repetido por famosos escritores, tais como Gide e Sartre, de que o romance seria mais verdadeiro, profundo e autêntico do que a autobiografia, superficial e esquemática, Lejeune propõe a noção de espaço autobiográfico, uma "forma indireta de pacto autobiográfico", que ele denomina também de "pacto fantasmático" (LEJEUNE, 2014, p. 50. Grifo do Autor). Trata-se não mais de uma explícita identidade do autor com o narrador através de elementos concretos (como os paratextos, por exemplo), mas de perceber na obra de ficção "fantasmas reveladores de um indivíduo" (2014, p. 50. Grifo do Autor). Por outras palavras, por conhecer a vida do autor através de suas autobiografias (e talvez biografia e outras informações, tais como entrevistas e relatos), o leitor é convidado a encontrar nas obras de ficção esses resíduos da vida empírica. Ao que parece, essa percepção não decorre apenas de um gesto deliberado do leitor, mas é encorajada, se este é o termo, pelos escritores, que, mesmo escrevendo autobiografias (ou simplesmente narrando suas vidas em entrevistas e relatos), declaram que elas são incompletas, fragmentárias, e que um eu mais verdadeiro e autêntico surgiria nas obras de ficção.

Certamente que a noção de espaço autobiográfico ainda está submetida à lógica do pacto, ou seja, a busca por elementos biográficos que permitam a identificação do autor 
com o narrador. No entanto, Lejeune admite que essa identificação pode se estabelecer de um modo mais indireto, propiciando uma abertura para uma relação autor-narrador mais sutil, ainda que dependente de uma concepção de ator que parece remeter à "pessoa real" do produtor da obra. De qualquer forma, a imagem de que a obra é assombrada por "fantasmas reveladores de um indivíduo" é interessante para se redimensionar o sentido da presença do autor empírico. Se, na esteira da sugestão de Lejeune, o indivíduo é fantasmático, não se trata mais de um "autor-presença", princípio produtor e explicativo do texto, mas de uma presença, por assim dizer, residual, difusa, que permite ao leitor estabelecer uma certa relação com um eu empírico, não no intuito de encontrar uma explicação para a obra, senão de perceber, quanto mais não seja, o quão diluído podem ser os liames que vinculam aquele eu empírico ao sujeito ficcional ou ao eu lírico.

Por este viés, a obra de Ana C. apresenta duas características importantes, que nos permitem considerar a hipótese da pertinência de um espaço autobiográfico: (a) a construção de simulacros de textos autobiográficos (cartas, diários) e (b) a tendência de explicitar (ou seria melhor dizer: "confessar"?), em sua obra poética, sua "fidelidade aos acontecimentos biográficos" - como podemos ler no seguinte texto, incluído em A teus pés:

O tempo fecha.

Sou fiel aos acontecimentos biográficos.

Muito mais do que fiel, oh, tão presa! Esses mosquitos que não largam!

Minhas saudades ensurdecidas por cigarras! O que faço aqui no campo declamando aos metros versos longos e sentidos? Ah que estou sentida e portuguesa, e agora não sou mais, veja, não sou mais severa e ríspida: agora sou profissional. (CESAR, 2013, p. 79)

A articulação dessas duas características evidencia uma espécie de apelo autobiográfico que não deve ser deixado de lado; ao contrário, os textos autobiográficos fingidos e as declarações de conteúdo confessional indicariam a sugestão de que, de um lado, a autobiografia é sempre um simulacro, no sentido de que é impossível captar o verdadeiro eu de um sujeito, e, de outro, que a ficção (ou, mais propriamente, a lírica) não apaga os traços dos "acontecimentos biográficos". Assim, a poesia de Ana C. aponta para um espaço autobiográfico em que o eu lírico é uma projeção fantasmática do sujeito empírico, um resíduo da experiência vivida que encontrou no poema sua manifestação. $\mathrm{O}$ eu que fala em seus poemas não é a Ana Cristina Cesar, mas um deslocamento desse eu empírico, sua redescrição retórica (para usar a expressão de Paul Ricoeur [2014]) operada pelo eu lírico. É o que Dominique Combe descreve através da figura da metonímia: a significação do sujeito lírico encontra a do sujeito empírico sem se confundir com ela (COMBE, 2010, p. 124).

Dessa maneira, a percepção de que o poema incorpora a experiência do poeta não configura um biografismo redutor, no sentido de procurar uma explicação para o poema apoiando-se nos acontecimentos biográficos do eu empírico. Trata-se, antes, de uma aproximação do poema empenhando-se em fugir da rígida e infrutífera dicotomia, de acordo com a qual ou o eu lírico é a imediata expressão do eu empírico ou o eu lírico só possui existência linguística, sem, portanto, remeter à experiência do poeta. $\mathrm{O}$ que 
importa não é reconstruir um percurso biográfico do poeta, mas tentar verificar de que modo a experiência vivida do poeta repercute afetiva e intelectualmente no texto poético, ou seja, o encontro do sujeito empírico e do eu lírico, sem que ambos se confundam ou que um se reduza ao outro.

"TANTAS FIZ..."

O título do poema "Samba-canção" remete ao subgênero musical originário do samba, cuja temática é, geralmente, o amor, a solidão e a dor de cotovelo (DOURADO, 2004, p. 291). Reforçando este aspecto, o poema de Ana C. estabelece um jogo intertextual, pela citação de um de seus versos, com a composição "Pra você gostar de mim" (1930), de Joubert de Carvalho, o grande sucesso na voz de Carmen Miranda:

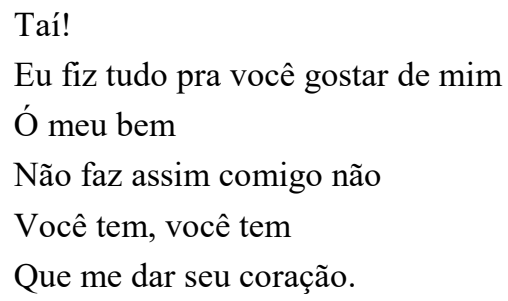

Neste sentido, pensando nos "acontecimentos biográficos", uma vinculação direta, sem mediações ou deslocamentos retóricos, do sujeito empírico ao eu lírico, imporia ao leitor a explicação da obra pelo fato ou acontecimento biográfico, esgotando, portanto, o significado do poema na percepção de que este dá expressão a uma frustração amorosa de Ana Cristina Cesar. Muito embora os poetas sejam suscetíveis a dores de cotovelo, gostaríamos de propor que o "acontecimento biográfico" não é a frustração amorosa. Logo no primeiro verso, o objeto cuja perda o eu lírico lamenta não é o amor de outra pessoa, mas os "tantos poemas". Esse não é o único deslocamento que o poema de Ana C. opera sobre a letra de Joubert de Carvalho. Como se observa, o poema de Ana C. suprime o objeto do verbo "gostar":

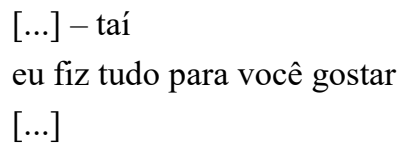

Assim, o que se reivindica não é gostar "de mim", do eu lírico ou da "pessoa" que se expressa no poema, mas de seus poemas. Não se deseja, portanto, o coração do interlocutor, mas sua atenção para os poemas, perdidos, talvez, em decorrência de o eu lírico não ter conseguido o "carinho" desse leitor que se almeja conquistar. Daí os múltiplos desdobramentos do eu lírico, que não mede "mesuras" e "estratégias", e que assume inúmeras e contraditórias máscaras ("mulher vulgar", "bem viada"), para alcançar seu objetivo. 
O conteúdo metalinguístico de "Samba-canção" permite-nos reconsiderar a dimensão autobiográfica do poema. Por certo, é possível identificar, pelos aspectos anteriormente mencionados (tom confessional, exposição do eu, marcas linguísticas que remetem a um sujeito feminino, coincidindo com o nome da autora do poema), uma determinada instância empírica, que não se confunde, entretanto, com a "pessoa real" chamada Ana Cristina Cesar. Por outras palavras, queremos dizer que o eu não é uma pura abstração que só tem forma no enunciado, uma vez que a "presença" de um autor empírico parece evidente ao leitor; contudo, seria problemático vincular essa voz a uma pessoa real, o que levaria a interpretação do poema à apreensão do acontecimento biográfico. Trata-se, antes, de acordo com as palavras de Combe, de um deslocamento do sujeito empírico que encontra no sujeito lírico sua significação (2010, p. 124). Assim, o eu que se expressa no poema não se confunde nem se reduz à "pessoa real" de Ana Cristina Cesar, mas trata-se de uma "redução fenomenológica" do eu empírico, conforme Paul Ricoeur (2014), ou seja, o eu lírico entendido como um sujeito retórico que suspende, de alguma forma, "a referencialidade do sujeito autobiográfico para melhor reencontrála” (COMBE, 2010, pp. 125-6).

Por esse viés, o eu que se manifesta no poema "Samba-canção", não sendo Ana Cristina Cesar, é uma de suas "máscaras": a poeta, quer dizer, a "pessoa real" que escreve poemas, cuja escrita lhe proporciona uma determinada experiência. Não se trata de um acontecimento biográfico, no sentido de um evento mais ou menos localizável na vida empírica, senão de uma experiência que, vivida por um sujeito empírico, afeta o texto, deixando nele a marca de um percurso intelectual. Experiência que, não se reduzindo à confissão de um fato, ocorre a um sujeito empírico e que, no poema, é matéria que transcende o meramente vivido para se constituir em reflexão acerca da condição do poeta e do poema. Por outras palavras, o eu lírico é inseparável da experiência do eu empírico, posto que a condição de poeta é inerente a sua existência; entretanto, pensando em termos de experiência, o que conta é "apenas a ressonância afetiva dos acontecimentos e dos fatos biográficos, que constitui a própria matéria do poema, muito mais que sua simples evocação, sob o modo descritivo e narrativo" (COMBE, 2010, p. 127), extraindo, pois, “o 'sentimento' da esfera psicológica individual, da biografia, para elevá-la ao patamar de categorias a priori da sensibilidade" (COMBE, 2010, p. 127) poética, criadora.

\section{CONSIDERAÇÕES FINAIS}

A noção de pacto autobiográfico, defendida por Lejeune, parece não dar conta da especificidade do gênero poético, tendo em vista uma reflexão acerca da dimensão autobiográfica do eu lírico. Ao reconsiderar a exclusão da lírica dos gêneros autobiográficos, Lejeune reduz o eu lírico à pessoa empírica do poeta, colocando, muito apressadamente, o eu lírico no mesmo horizonte teórico do narrador das narrativas autobiográficas. Compreendemos que o gênero lírico possui uma dimensão autobiográfica, que não pode ser descrita, contudo, com a simples identificação do eu lírico com o eu empírico, o autor do poema, esquema epistemológico que configura o famoso pacto referencial. Se é certo que o poema possui uma referencialidade, através da qual é possível vincular, de algum modo, a voz do poema a um sujeito empírico, o que 
importa não são tantos os acontecimentos ou fatos biográficos na origem do poema, mas, antes, a experiência que o eu lírico eleva a um patamar que não se reduz às contingências anedóticas de sua biografia. No caso analisado, é a experiência da escrita de poemas (e não a vida amorosa ou qualquer outro aspecto da vida de Ana Cristina Cesar) que propicia estabelecer uma identidade entre o eu lírico e o eu empírico. No entanto, não se trata da identidade autor-narrador, conforme as palavras de Lejeune, mas de um deslocamento do eu empírico para o eu lírico, o encontro, conforme postula Combe, do sujeito empírico e do eu lírico, sem que ambos se confundam ou que um se reduza ao outro.

\section{REFERÊNCIAS}

BARTHES, Roland. A morte do autor. O rumor da língua. Trad. Mario Laranjeira. São Paulo: Martins Fontes, 2004.

CAMARGO, Maria Lucia de Barros. Atrás dos olhos pardos; uma leitura da poesia de Ana Cristina Cesar. Chapecó: Argos, 2003.

CESAR, Ana Cristina. Poética. São Paulo: Cia, das Letras, 2013.

COMBE, Dominique. A referência desdobrada. O sujeito lírico entre a ficção e a autobiografia. Trad. Iside Mesquita; Vagner Camilo. Revista USP, n.84, p.112-128, dez/fev. 2009-2010.

DOURADO, Henrique Autran. Dicionário de termos e expressões da música. São Paulo: Editora 34, 2004.

HANSEN, João Adolfo. Autor. In: JOBIM, José Luís (org.). Palavras da crítica. Rio de Janeiro: Imago, 1992.

LEJEUNE, Philippe. Le pacte autobiographique, Paris: Ed Seuil, 1975.

LEJEUNE, Philippe. O pacto autobiográfico; de Rousseau à Internet. Trad. Jovita Maria Gerheim Noronha; Maria Inês Coimbra Guedes. Belo Horizonte: Editora UFMG, 2014.

RICOEUR, Paul. O si-mesmo como um outro. Trad. Ivone Benedetti. São Paulo: Martins Fontes, 2014. SISCAR, Marcos. Ana Cristina Cesar. Rio de Janeiro: Eduerj, 2011. (Col. Ciranda da Poesia).

Recebido em 02/02/2016. Aprovado em 30/02/2016.

Title: Lyric and autobiographical space in "Samba-canção" by Ana Cristina Cesar

Abstract: The present paper aims at reflecting upon the autobiographical dimension of the persona. To do so, we analyze the importance of biographical references in the poem "Samba-canção" by Ana Cristina Cesar based on the concepts of autobiographical pact, autobiographical space and poetic experience.

Keywords: Lyric. Autobiography. Autobiographical space. Poetic experience. Ana Cristina Cesar.

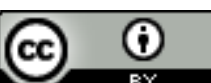

Este texto está licenciado com uma Licença Creative Commons Atribuição 4.0 Internacional. 